\title{
Review \\ Fabricating Lattice Structures via 3D Printing: The Case of Porous Bio-Engineered Scaffolds
}

\author{
Antreas Kantaros* ${ }^{(\mathbb{D}}$ and Dimitrios Piromalis \\ Department of Industrial Design and Production Engineering, University of West Attica, 12241 Athens, Greece; \\ piromali@uniwa.gr \\ * Correspondence: akantaros@uniwa.gr
}

check for updates

Citation: Kantaros, A.; Piromalis, D. Fabricating Lattice Structures via 3D Printing: The Case of Porous

Bio-Engineered Scaffolds. Appl. Mech. 2021, 2, 289-302. https://doi.org/ 10.3390/applmech2020018

Received: 27 April 2021

Accepted: 21 May 2021

Published: 25 May 2021

Publisher's Note: MDPI stays neutral with regard to jurisdictional claims in published maps and institutional affiliations.

Copyright: (C) 2021 by the authors. Licensee MDPI, Basel, Switzerland. This article is an open access article distributed under the terms and conditions of the Creative Commons Attribution (CC BY) license (https:/ / creativecommons.org/licenses/by/ $4.0 /)$.

\begin{abstract}
Over time, the fabrication of lattice, porous structures has always been a controversial field for researchers and practitioners. Such structures could be fabricated in a stochastic way, thus, with limited control over the actual porosity percentage. The emerging technology of 3D printing, offered an automated process that did not require the presence of molds and operated on a layer-by-layer deposition basis, provided the ability to fabricate almost any shape through a variety of materials and methods under the umbrella of the ASTM terminology "additive manufacturing". In the field of biomedical engineering, the technology was embraced and adopted for relevant applications, offering an elevated degree of design freedom. Applications range in the cases where custom-shaped, patient-specific items have to be produced. Scaffold structures were already a field under research when 3D printing was introduced. These structures had to act as biocompatible, bioresorbable and biodegradable substrates, where the human cells could attach and proliferate. In this way, tissue could be regenerated inside the human body. One of the most important criteria for such a structure to fulfil is the case-specific internal geometry design with a controlled porosity percentage. 3D printing technology offered the ability to tune the internal porosity percentage with great accuracy, along with the ability to fabricate any internal design pattern. In this article, lattice scaffold structures for tissue regeneration are overviewed, and their evolution upon the introduction of 3D printing technology and its employment in their fabrication is described.
\end{abstract}

Keywords: 3D printing; lattice structures; tissue engineering; regenerative medicine; scaffold

\section{Introduction}

In the biomedical field, the incorporation of 3D printing technology in the fabrication of highly specialized, patient-specific structures is immense. A number of researchers are looking into ways in which 3D printing can be applied to medical implant design and manufacturing, tissue engineering and regenerative medicine. Due to the demand of extremely high precision manufacturing characteristics with such structures, 3D printing technology is ideal for the task.

The act of 3D printing involves a process of fabricating three-dimensional objects derived from a digital CAD file. This is achieved using material layer deposition processes (also referred as "AM" processes), where the deposition of successive material layers leads to the final creation of an actual physical part. Each layer can be visualized as a thin sliced horizontal cross-section of the final object by tuning specific process parameters [1-3]. This technology is known as "rapid prototyping" and allows swift and easy transition from CAD design concepts to the fabrication of physical objects. Its contribution is immense in bridging the time gap between the product design and the prototype fabrication, hence the term "rapid". This technology is often described as "the third industrial revolution" [4], and, through a series of technical advances, it can nowadays be considered as an end product manufacturing method as well. The vast advantages of this technology, due to the complete absence of pre-shaped molds and human intervention during the fabrication stage, offer the ability to fabricate complex geometries with controlled characteristics. 
Bearing in mind the aforementioned unique advantages that 3D printing technology offers, numerous cases of its employment in the biomedical field have been reported in the literature. All of these cases share the common consensus of utilizing this technology in order to fabricate structures with well-defined geometrical characteristics that can be altered on demand, as well as tailored mechanical behavior. A number of companies in Italy have utilized 3D printing techniques to produce a great number of hip implants made from metal, for human use [2]. Due to the demand for extremely high precision manufacturing characteristics when producing hip implants, 3D printing technology is ideal for the task. Thus, thousands of acetabular hip cups have been produced using 3D printing techniques. Lima Corporate was able to produce more than 40,000 hip cups in the last ten years. The company utilizes the electron beam melting (EBM) 3D printing technique, which is considered a state-of-the-art method. Researchers are focusing on the design and production of implants made from titanium featuring tailored mechanical behavior that resembles the stiffness of bone tissue [5]. Meanwhile, Walter Reed Army Medical Center has been able to fabricate a small batch of 37 cranial implants by utilizing electron beam melting (EBM), a 3D printing process from Arcam, Sweden [6]. Figure 1 shows 3D-printed hip and knee implants.

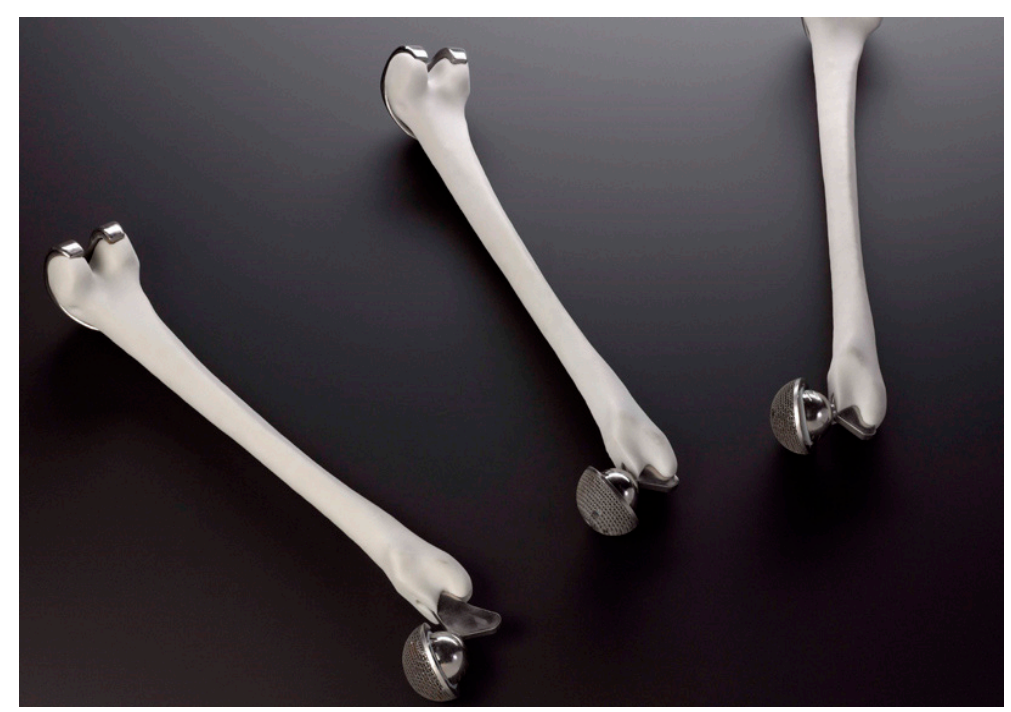

Figure 1. 3D-printed hip and knee implants [2].

Being able to address mass human skull injuries requires the fabrication and use of patient-specific cranial implants. Researchers have managed to design custom-made cranial plates using advanced automatic techniques along with 3D printing biocompatible metal material, again, by using electron beam melting (EBM) technology [7]. In addition, studies have been conducted to investigate the processing and the use of powder calcium phosphate material for fabricating implants for reconstructing cranial and maxillofacial topology defects. The fabrication of the implants was conducted by utilizing a commercially available 3D printing powder apparatus. Figure 2 depicts a skull with 3D-printed calcium phosphate embedded implants [8].

The process stages, right from the initial data acquisition to the end-printing of the implants, showed no practical implications, while individual implants showed a high degree of fitting. Therefore, 3D printing of calcium phosphate cement powder is now considered a promising new method for the fabrication of biodegradable synthetic patientspecific craniofacial implants [8]. Another case concerns the fabrication of biological models that allow the visualization of facial skeletons, which are being used at an increasing rate for diagnosis and pre-surgical planning for congenital treatment, developmental and post-traumatic factors in the greater facial region. Being able to fabricate graspable 3D models applied in pre-surgical planning offers the maxillofacial surgeon with vital 
information regarding the spatial displacements in the topology defect area that allows accurate definition of the deformity $[9,10]$. Graspable three-dimensional objects surpass most of the potential limitations that 3D visualizations feature, one of which is their display on flat screens. For example, by employing 3D printing technology, the printed heart models helped researchers to assess the cardiac problems of their patients [11].
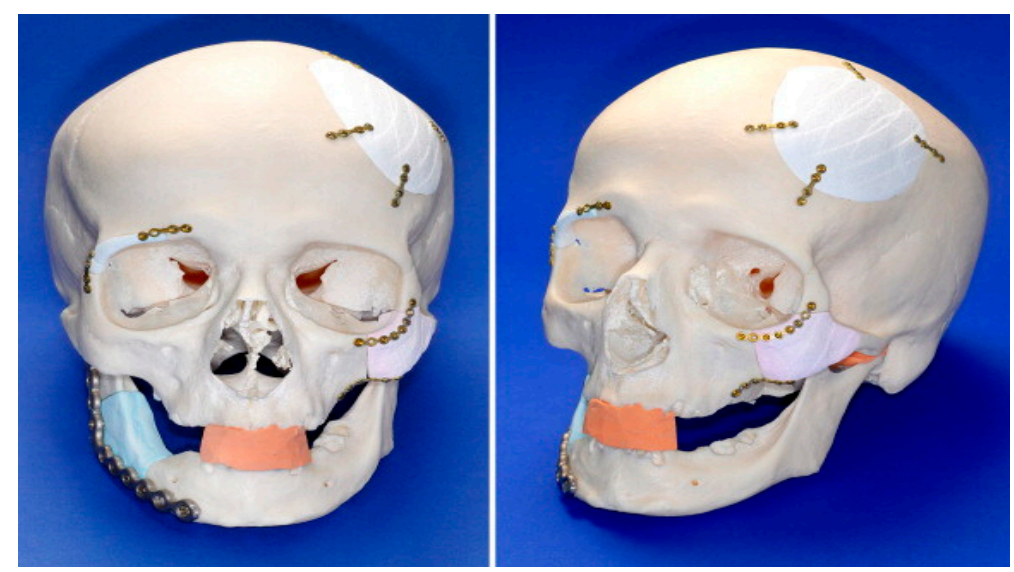

Figure 2. Skull with 3D-printed calcium phosphate embedded implants [8].

Another medical field that utilizes 3D printing technology is tissue engineering. Tissue engineering is a novel, interdisciplinary sector combining the basic principles of engineering and biology in order to come up with elevated biological functions. Regarding clinical applications, one of the most important targets of tissue engineering is to surpass the numerous barriers imposed by current treatments that are currently based solely on organ transplants and biomaterial use for implantation [12]. Organ and tissue malfunctions are a major issue in the human health agenda. Especially in the cases where the human body cannot reverse this situation by self-healing using its own resources, targeted medical assistance is required. When tissues or organs have been severely damaged or destroyed by causes such as cancer, congenital anomaly or trauma, conventional pharmaceutical treatments cannot be applied.

Transplantation medicine is the field that has offered solutions to such cases for almost half a century now. While being one of the most visionary areas of modern medicine, it still suffers from various limitations. Donated organ availability is probably the largest problem, with thousands of patients waiting on transplant lists while their quality of life becomes constantly compromised due to their unresolved health problems. Another drawback that often arises is immunological rejection. The donated organ can only be used for transplantation if it is an exact "match" in immunological terms for the recipient. In addition, the recipient in most cases must receive extensive immunosuppressant therapy as the only way to deal with a potential organ rejection. Unfortunately, a number of side effects arise because these drugs tend to suppress the patient's natural immunological response to pathogens, leading to an elevated percentage of in-hospital-acquired infections. In addition, both living and cadaveric transplants undergo ischemic damage for the period between organ removal and transplantation. This is minimized by reducing storage temperature in order to prevent cell degradation [13].

Approximately three decades ago, a newly introduced, interdisciplinary field combining the core principles of engineering and biology emerged. Referred as "tissue engineering", it combines the core principles of engineering and life sciences towards the development of biocompatible substitutes that have the ability to restore, maintain and/or boost tissue function [13]. The term "tissue engineering" was first coined by Y.C. Fund at the National Science Foundation convention in 1987.

Despite the fact that the sector of tissue engineering may be newly introduced, the idea of tissue substitution was first expressed in the 16th century. Gasparo Tagliacozzi 
(1546-1599), Professor of Surgery and Anatomy at the University of Bologna, first referred to a nose replacement constructed from a forearm flap in "De Custorum Chirurigia per Insitionem" (The Surgery of Defects by Implantation), first published in 1597 [14]. The earliest clinical application of human cells in the field of tissue engineering involved the skin tissue by utilizing fibroblasts, keratinocytes, or a scaffold (acting as a tissue substrate). While this was in the 1980s, an attempt was made to fabricate alveolar bone and periodontal tissues by using membranes that produced a controlled environment for the topological defect site for tissue regeneration by not allowing fibroblasts to invade the area. Researchers [15] have focused on cell transplantation by utilizing bioabsorbable synthetic polymers as substrates. In another case, the regeneration attempt of rabbit articular surfaces by using allograft chondrocytes along with collagen gel was also reported [16]. A literature report by Langer and Vacanti [13] under the title Tissue Engineering is considered a great contribution towards promoting tissue engineering research on a worldwide scale [17].

The first decade of the 21st century is linked with the first successful attempts of creating the first lab-grown organs by using 3D bioprinters. The contribution of Anthony Atala is considered as immense in this field, where Dr. Atala leads a team of more than 400 researchers focused on developing cell therapies, tissue engineering constructs and organs for more than 40 different areas of the body [18]. In addition, he is considered as the creator of 3D bioprinters [19] and, in 2006, he and his team developed the first lab-fabricated organ (a human bladder) to be implanted into a human [20]. Dr. Paolo de Coppi's work is also considered as significant in the field, with cases such as a tissue engineered tracheal replacement in a 12-year-old child being reported [21]. A two-year follow-up showed the success of this effort [21]. In another case, he and his team made a successful attempt to create in vivo-engineered well-vascularized muscle tissues [22].

Lattice tissue engineering structures must be the result of precise and sophisticated efforts in order to be implanted to a patient. An artificial structure that will provide the proper substrate for three-dimensional tissue formation is the final target of this effort. This kind of structures, commonly named as "scaffolds", must act as bioresorbable constructs in the specific area of the defect acting as cell-encapsulated tissue constructs containing cells/hydrogels $[23,24]$. Such lattice structures can be can be distinguished as "acellular scaffolds" (scaffolds without cells, such as hip and knee implants, cranial implants) and "cellular scaffolds" (scaffolds containing cells, such as tissue-engineered skin constructs). Scaffolds should meet certain demands. Adequate mechanical behavior is considered one of the most important aspects, because they must provide mechanical stability both during the healing and degradation stages. Controlled porosity is another factor, where an interconnected pore network is considered a necessity. In addition, the ability to be fabricated in a variety of shapes and sizes is crucial [25]. 3D printing techniques provide great potential in this area, by offering dimensional accuracy, a high degree of reproducibility and the ability to manufacture a pre-determined $100 \%$-interconnected porosity network at various sizes [26,27]. A number of research groups have successfully fabricated scaffold structures using 3D printing techniques [26,28-40].

In addition, the literature suggests that different 3D printing methods are used depending on whether the scaffold is acellular or cellular. In the case of acellular scaffolds, Lowther et al. found that metal implant (metallic skeletal endoprostheses) production has greatly benefited by adopting powder bed fusion 3D printing technologies such as SLM, SLS and EBM [41], while Zein et al. demonstrated that FDM 3D printing technology was successfully used to fabricate a porous scaffold from poly-e-caprolactone (PCL) [42]. On the other hand, bioprinting methods are used for the fabrication of cellular scaffolds. Ozbolat and Hospodiuk underlined the extrusion-based bioprinting (EBB) method's ability to generate viable end products for tissue engineering purposes [43]. The use of inkjet bioprinting is also referred in the literature as a promising technology for scaffold building and cell depositing [44,45]. Wei Long Ng et al. also report vat polymerization (VP)-based bioprinting and ultraviolet-assisted extrusion-based (UAE) bioprinting, as newly introduced and very promising bioprinting techniques for various tissue engineering applications, 
featuring elevated fabrication accuracy $[46,47]$. Figure 3 shows a tissue engineering scaffold fabricated with a 3D-Bioplotter [48].

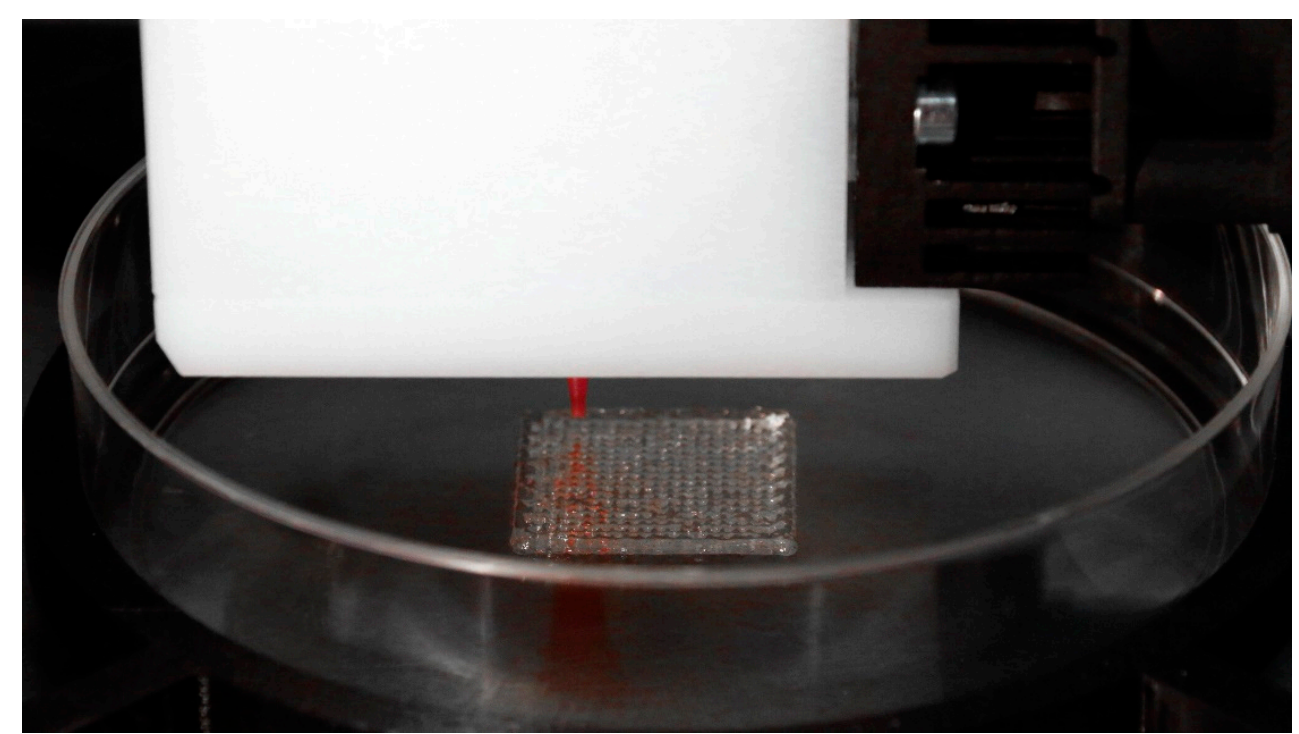

Figure 3. Tissue engineering scaffold fabricated with a 3D-Bioplotter [34].

\section{Scaffold Structures Modus Operandi Criteria}

The limitations of current treatments based on organ transplantation and biomaterial grafting have to be taken under great consideration when designing such structures [12]. The ultimate goal is to have the ability to regenerate each individual patient's own tissues and organs to avoid low bio-functionality issues, as well as severe immune reactions [17]. Considering that every engineered organ uses the recipient's own tissue, immunological reactions are minimized. A simple cell injection to a target sites with destroyed tissue cells does not offer proper regeneration. The majority of large-sized tissues and organs featuring well-structured 3D shapes require adequate support in order to be differentiated from cells [17].

In order to meet these criteria, an artificial structure providing the proper conditions for $3 \mathrm{D}$ tissue regeneration is being proposed. The prevailing term for such structures is the "scaffolds", also dubbed templates or artificial extracellular matrixes (ECMs) [17]. Such assembly of cells, signals and scaffolds is commonly referred to as the tissue engineering triad, and is graphically depicted in Figure 4.

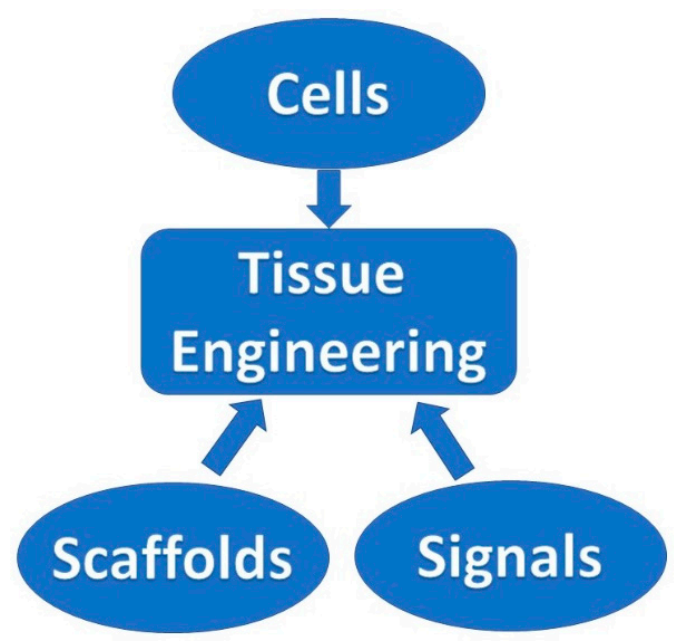

Figure 4. Assembly of cells, signals and the scaffold that performs as a support arrangement for tissue formation. 
The major role of such a structure resembles that of a natural ECM boosting the proliferation, differentiation and biosynthesis of the relevant cells. Moreover, such a structure implanted at the site of the topological defect will avert non-relevant cells from invading the area [17]. The relevant cells proliferate through the cell culture, and are seeded into the lattice scaffold structure, which accommodates and acts as a substrate that boosts the expansion of new cells in all three dimensions of the area [49]. A tissue engineering scaffold model is depicted in Figure 5.

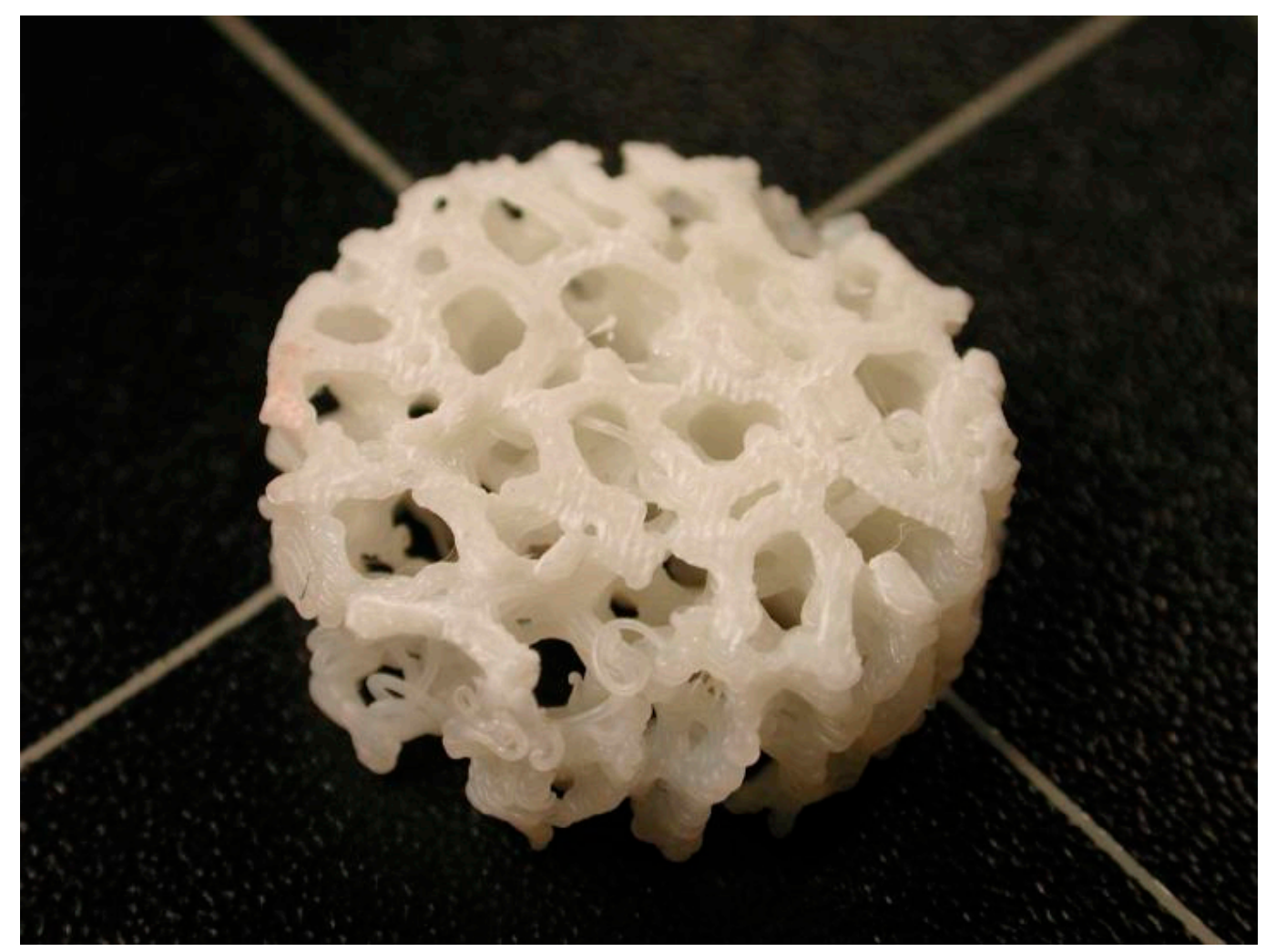

Figure 5. Close-up picture of a 3D-printed lattice scaffold structure model.

In the previous years, scaffold structures were made from a variety of biomaterials and fabricated by utilizing various methods. There are thousands of cases where different scaffolds were fabricated with the goal of regenerating different types of tissues and organs. Regardless of the tissue classification, the suitability of the scaffold was not always accomplished to a satisfactory degree due to their demanding role upon implantation.

The first benchmark of a successful lattice scaffold structure used in tissue engineering is biocompatibility. Bearing this in mind, cells should be able to adhere, function normally and migrate inside the artificial structure. Upon implantation, the scaffold substrate must not cause any immunological reaction leading to a potential severe inflammatory response [14].

Secondly, the lattice scaffold structure must provide, with topology required, sufficient mechanical behavior in order to provide the desired mechanical stability during both healing and degradation stages [12,50]. Considering that the 3D scaffold might have to exhibit temporary load-bearing characteristics, its mechanical behavior should be similar to or greater than the specific topological load characteristics of the implantation area, without exhibiting fatigue or failure [10].

In regenerative approaches, the scaffold's role is to serve as a replaceable construct in order to gradually permit the body's own cells to gradually take over the implanted structure. The scaffold's role must not be confused with that of permanent implants. In this context, it should be biodegradable in a way that allows cells to eventually make their own, unique, extracellular matrix. Potential side-products caused by its degradation should also 
exhibit non-toxic characteristics that will lead to its exit from the body without causing implications to other organs $[50,51]$. Tissue engineering strategies nowadays being slowly established in clinical practice, leading towards this direction [14,52].

Another key parameter for lattice scaffold structures used in this field is their pore architecture. Thus, the structure must exhibit high porosity degrees with well-formed, interconnected pore networks, leading to adequate fluidic motion, which leads to cell growth, nutrient transport and elevated metabolic waste [50,51]. The potential problems of cell core degradation, caused by limited vascularization from such structures, are numerous [14]. Another key factor is the size of the pores themselves. Cells tend to interact with the implanted lattice scaffold structures via ligands on their porous surfaces, something that is highly shape-dependent. In this context, the porosity degree of the structure should be such that it will allow cell migration and ligand bonding, and on the other hand, provide adequate adhesion with the scaffold's surface [53]. The literature suggests that different cell types tend to prefer specific porosity degrees and architectures $[14,54]$. Both porosity and pore size have an effect on fluid shear stress which is also a critical parameter in a scaffold structure due to its role in controlling fluid perfusion through the scaffold's pore network. Elevated stress percentages are linked with limited attachment of the cells to the scaffold's surface, and previously attached cells may also suffer [55]. Researchers have demonstrated that random architecture of a scaffold can potentially lead to high shear stress percentages and scaffolds with homogeneous pore distribution are, therefore, preferable due to their ability to enable precise control over the shear stresses imposed on cells [56,57]. In addition, inadequate control over the porous architecture might lead to diverse mechanical behavior characteristics for the same scaffold design $[28,58]$. Lattice scaffold structures feature CAD-controlled architectures with controlled porosity percentage and pore size, as well as homogeneous pore distribution.

Porosity percentages of CAD software-designed lattice scaffold structures can be determined according to the following equations [35]:

$$
\text { Porosity }_{C A D}=\left(1-\frac{\mathrm{V}_{\text {str }}}{\mathrm{V}_{\text {cub }}}\right) \times 100 \%
$$

where $\mathrm{V}_{\text {str }}$ stands for the volume of the struts and $\mathrm{V}_{c u b}$ stands for the overall volume of the scaffold.

$$
\text { Porosity }_{A M S}=\left(1-\frac{\rho_{s c}}{\rho_{0}}\right) \times 100 \%
$$

where $\rho_{0}$ stands for the density of the material to be used in the 3D printing fabrication of the structure while $\rho_{s c}$ stands for the density of the 3D-printed scaffolds themselves, calculated by taking into account the volume and weight of the structures.

\section{Scaffold Desired Mechanical Behavior Characteristics}

One of the most crucial specifications for a scaffold is its mechanical behavior that: (a) should be consistent with the host, thus providing the necessary mechanical performance during the alleviation process; and (b) should permit surgical handling and manipulation during implantation, a crucial factor, especially in the cases of cardiovascular and orthopedic applications [29].

Another factor that must be taken under consideration is that rates of healing are highly age-dependent. In younger ages, fractures tend to heal up to a sufficient point of weight-bearing ability in about six weeks, while fully gaining mechanical integrity about one year after fracture. On the other hand, in the elderly the rate of healing is slower which is also the case for orthopedic applications. A vast number of materials exhibiting adequate mechanical propertied have been introduced. These are also capable of exhibiting the desired high porosity degrees while demonstrating high potential in vitro. However, during in vivo implantation, they do not perform adequately because of their limited ability to exhibit the desired vascularization percentages according to specific cell demands. 
The need for adequate vascularization is one of paramount importance. It can be fulfilled by retaining a three dimensional and highly porous architecture that will assure adequate fluid perfusion under any conditions. A potential structural failure under mechanical loading can be catastrophic for the scaffold. Local or even global densification phenomena can destroy the scaffold's interconnected pore network and disrupt the flow transport of nutrients and metabolic waste. Therefore, an ideal balance between mechanical behavior and porous architecture is vital towards fabricating an artificial lattice scaffold structure that will fulfill its role [50].

\section{The Potential of 3D-Printed Scaffold Structures}

As stated before, 3D printing exceeds as an ideal method for scaffold fabrication, since it allows both the exact attribution of the external shape of the scaffold (which is patientand topology-specific) along with a pre-defined internal pore geometry (which differs according to the purpose that each scaffold must fulfill) [59]. The importance of these parameters in the scaffold's successful operation is also described in the literature.

Barba et al. describe that 3D printing methods lead to the fabrication of well-defined lattice scaffold structures with high osteogenic potential from hydroxyapatite material. More specifically, it is described that spherical, concave macropore scaffold designs tend to increase material resorption and bone regeneration rates, especially when compared to scaffolds featuring orthogonal-patterned struts and prismatic, convex macropore network [60]. Kantaros et al. have investigated the mechanical behavior characteristics of 3D-printed scaffold prototypes featuring different internal pore geometries but similar external dimensions, and, through, a series of experiments, FEA and CFD simulations and numerical power laws implementation depicted that the internal pore design offers completely different mechanical behavior and fluidic characteristics [61].

Habib et al. report the use of a promising, newly introduced 3D printing technology, coined under the term of "multi jet fusion (MJF)", which was used in order to fabricate lattice scaffold structures. It was shown that the global energy absorption of the produced lattices can be further enhanced by controlling and manipulating their inner micro-topology architecture, something that can be achieved only via using 3D printing methods. The findings showed superior performance in energy absorption percentages compared to conventionally fabricated stochastic foams [62].

Hollister et al. also report that when taking into account all available manufacturing techniques, 3D printing techniques feature the potential of fabricating scaffolds of complex anatomic shaping and well-defined pore architecture. In addition, the aforementioned techniques offer the ability to fabricate such lattice structures exhibiting elevated fluidic mass-transport properties, along with increased fabrication repeatability [63].

Krishna et al. also stress the importance of a well-defined internal network that is desired in order to provide the right cell attachment and growth rates in scaffold structures. In their research, which describes the fabrication of a bio-engineered scaffold for soft tissue regeneration (i.e., human skin) they stress the immense contribution of the FDM 3D printing technique in fabricating such a structure that leads to improved new tissue growth percentages [64].

Ning et al. describe the implementation of extrusion-based bio-printing that not only allows the fabrication of a sophisticated scaffold design using biomaterials, but also allows the simultaneous, manipulated cell deposition on the scaffold during the printing process [65].

Nurulhuda proposes a new approach technique that employs the "DLP" 3D printing process (which utilizes a DLP projector to cure photosensitive resin) in fabricating a lattice scaffold structure out of polyethylene glycol diacrylate (PEGDA), which is filled with a percentage of aramid nanofibers (ANFs). Findings exhibited a high degree of biocompatibility along with elevated mechanical behavior [66]. 
Taylor et al. report the successful 3D printing work in which NiTi powder-based inks were used for bone regeneration targeted scaffold structures that were subsequently seeded with mesenchymal stem cells derived from adult humans. These structures showed excellent viability, proliferation, and extracellular matrix deposition during 14 days in a culture environment [67].

Yang et al. reported the fabrication of a composite lattice scaffold structure that featured dual-function ability. On one hand, the structure prevented bacterial infection while, on the other hand, it promoted bone regeneration in infected bone cases [68]. Again, this would not have been able without the contribution of 3D printing methods.

Remaining in the sector of lattice scaffold structures featuring hierarchical porous structures and tunable multifunctional performance, $\mathrm{Hu}$ et al. proposed the fabrication of bioactive nanoparticle/poly (e-caprolactone) (BNPCL) scaffolds featuring hierarchical porous structures relying on solvent evaporation of 3D-printed water-in-oil high internal phase emulsion (HIPE) templates [69]. Alison et al. proposed the use of ink formulations designed to enable 3D printing of hierarchical materials capable of exhibiting porosity at the nano-, micro- and macro-scales [70]. Using a different approach, porosity is accomplished upon removal of nanodroplets and microscale templates that were present in the initial ink [70]. Minas et al. report the use of emulsion and foams as 3D printing raw materials, leading to controlled and high porosity (up to 94\%) ceramic lattice scaffold structures [71]. Lefevere et al. proposed the use of a method for the robocasting of zeolite, where 3D-printed monoliths were fabricated directly using ZSM-5 as active material resulting in highly controlled porosity and elevated mechanical behavior [72]. In addition, $\mathrm{Ng}$ et al., focusing on the fabrication of 3D hierarchical porous collagen-based hydrogel constructs, proposed a single-step bioprinting process based on printable macromolecule-based bio-inks [73], while Chen et al. also used bioprinting technology to fabricate a calcium silicate complex hierarchical porous scaffold focused on the regeneration of defective complex hard tissues in deep bone structures [74]. Table 1 refers to different 3D printing techniques/strategies to fabricate porous scaffold structures.

Table 1. Different 3D printing techniques/strategies to fabricate porous scaffold structures.

\begin{tabular}{|c|c|c|c|}
\hline & 3D Printing Techniques & Materials & Strategy/Printing Process \\
\hline \multirow{3}{*}{ Acellular Scaffolds } & $\begin{array}{l}\text { Powder Bed Fusion } \\
\qquad(\mathrm{PBF}) \\
(\mathrm{SLM} / \mathrm{SLS} / \mathrm{EBM})\end{array}$ & $\begin{array}{l}\text { Titanium/Aluminum } \\
\text { Cobalt-Chromium- } \\
\text { Molybdenum alloys in } \\
\text { powder form [41] }\end{array}$ & $\begin{array}{c}\text { Layers of powder thermally fused } \\
\text { by an energy source (laser or } \\
\text { electron beam) }\end{array}$ \\
\hline & Direct Energy Deposition (DED) & $\begin{array}{l}\text { Metal alloys in powder or } \\
\text { wire form } \\
\text { (titanium/aluminum alloys, } \\
\text { refractory metals such as } \\
\text { tantalum, tungsten, niobium) }\end{array}$ & $\begin{array}{l}\text { The feedstock material is } \\
\text { forwarded through the nozzle, } \\
\text { where it is melted by a focused } \\
\text { heat source (laser or electron } \\
\text { beam) and deposited on the build } \\
\text { platform. Both nozzle and heat } \\
\text { source are attached on a robotic } \\
\text { arm or a gantry system }\end{array}$ \\
\hline & $\begin{array}{l}\text { Fused Deposition Modelling } \\
\text { (FDM) }\end{array}$ & $\begin{array}{c}\text { Biodegradable and } \\
\text { biocompatible polymers in } \\
\text { filament form such as PCL etc. } \\
{[42,75]}\end{array}$ & $\begin{array}{c}\text { The filament material is } \\
\text { forwarded to the extrusion nozzle } \\
\text { where it is heated and melted. It } \\
\text { is then deposited on a build } \\
\text { platform enclosed in a } \\
\text { heated chamber }\end{array}$ \\
\hline
\end{tabular}


Table 1. Cont.

\begin{tabular}{|c|c|c|c|}
\hline & 3D Printing Techniques & Materials & Strategy/Printing Process \\
\hline \multirow{6}{*}{ Cellular Scaffolds } & $\begin{array}{l}\text { Extrusion Based Bioprinting } \\
\text { (EBB) }\end{array}$ & $\begin{array}{l}\text { Hydrogel solutions, bio-ink } \\
\text { materials [43] }\end{array}$ & $\begin{array}{l}\text { Bio-ink material is dispensed with } \\
\text { high precision resulting in } \\
\text { targeted cell deposition. Cells are } \\
\text { encapsulated in cylindrical } \\
\text { filaments forming pre-determined } \\
\text { 3D structures }\end{array}$ \\
\hline & Laser Based Bioprinting * (LBB) & $\begin{array}{l}\text { Cells of various types, culture } \\
\text { medium [76] }\end{array}$ & $\begin{array}{l}\text { A laser beam focused through a } \\
\text { low numerical value aperture } \\
\text { lens, resulting in the deposition of } \\
\text { cells through culture media on } \\
\text { pre-designated spots on a } \\
\text { glass surface }\end{array}$ \\
\hline & $\begin{array}{l}\text { Inkjet Based Bioprinting * (DNA } \\
\text { and protein printing) }\end{array}$ & $\begin{array}{c}\text { Hydrogels (Alginate, PEG, } \\
\text { Alkanethiols etc.), binders } \\
\text { (acrylic ink, phosphoric acid, } \\
\text { PVA etc.) Polymers (PCL, } \\
\text { PLA, PLGA etc.) dissolved or } \\
\text { dispersed in organic solvents } \\
\text { [44,77] }\end{array}$ & $\begin{array}{l}\text { Modified commercial inkjet } \\
\text { printers that deposit bio-ink } \\
\text { material that forms } \\
\text { self-assembled layers }\end{array}$ \\
\hline & Cell inkjet Bioprinting * & $\begin{array}{l}\text { Cells of various types, } \\
\text { bio-paper [44] }\end{array}$ & $\begin{array}{l}\text { Direct deposition of cells using } \\
\text { printheads on a substrate }\end{array}$ \\
\hline & Microvalve-based bioprinting * & $\begin{array}{l}\text { Hydrogels of specific } \\
\text { viscosity [45] }\end{array}$ & $\begin{array}{l}\text { The process uses a platform and } \\
\text { multiple electromechanical } \\
\text { micro-valve printheads } \\
\text { depositing bio-ink }\end{array}$ \\
\hline & VAT Polymerization & $\begin{array}{l}\text { Bio-resins including PEGDA } \\
\text { and GelMA etc. [46] }\end{array}$ & $\begin{array}{l}\text { Specific wavelength laser is } \\
\text { emitted in the bio-resins } \\
\text { achieving its curing via } \\
\text { photopolymerization processes }\end{array}$ \\
\hline
\end{tabular}

* These 3D printing techniques comprise the drop-on-demand (DOD) inkjet bioprinting category.

\section{Conclusions}

Throughout time, the fabrication of lattice, porous structures has always been a controversial field for researchers and practitioners. Such structures could be fabricated, but with limited control over the actual porosity percentage. What is more, complex geometry internal patterns could not be easily fabricated because the presence of molds that had to be removed in casting processes was a big barrier to overcome. Therefore, the fabrication of such structures, in one piece, concerned simplistic designs with limited applications.

The emerging technology of 3D printing, especially after 2010, when a number of relevant patents expired, broadens the horizon in this field. The automated process, that did not require the presence of molds, and operated on a layer-by-layer deposition basis, provided the ability to fabricate almost any shape through a variety of materials and methods.

These advantages were soon realized by the interdisciplinary composition of research teams focusing on the continuously evolving sector of biomedical engineering and the technology was embraced and adopted for relevant applications. Offering an increased degree of design freedom, applications ranged in the cases where custom-shaped, patientspecific items had to be produced. The sector of implant fabrication was one of the first sectors to use this technology, offering the ability to fabricate implants of a specific shape according to the patient's needs.

Scaffold structures were already a field under research when 3D printing was introduced. These structures had to act as biocompatible, bioresorbable and biodegradable substrates, where the human cells could attach and proliferate. In this way, tissue could be regenerated inside the human body. However, such structures must fulfill a number of 
criteria to be considered successful in their role. One of these criteria is the case-specific internal geometry design with controlled porosity percentage. 3D printing technology offered the ability to tune the internal porosity percentage with great accuracy along with the ability to fabricate any internal design pattern.

In conclusion, 3D printing technology proved to be a stepping stone towards overcoming a number of barriers in the biomedical field. One of them was its contribution in fabricating patient-specific tissue regeneration lattice structures called scaffolds. The variety of available materials to be 3D-printed, along with the evolution of this technology, suggests that this field has a great future potential.

Funding: This research received no external funding.

Institutional Review Board Statement: Not applicable.

Informed Consent Statement: Not applicable.

Data Availability Statement: Not applicable.

Conflicts of Interest: The authors declare no conflict of interest.

\section{References}

1. Kantaros, A.; Piromalis, D. Employing a Low-Cost Desktop 3D Printer: Challenges, and How to Overcome Them by Tuning Key Process Parameters. Int. J. Mech. Appl. 2021, 10, 11-19. [CrossRef]

2. Kantaros, A.; Giannatsis, J.; Karalekas, D. A novel strategy for the incorporation of optical sensors in Fused Deposition Modeling parts. In Proceedings of the International Conference on Advanced Manufacturing Engineering and Technologies, Stockolm, Sweden, 27-30 October 2013; Universitets service US AB, KTH Royal Institite of Technology: Stockholm, Sweden, 2013; ISBN 978-91-7501-893-5.

3. Kantaros, A.; Karalekas, D. FBG based in situ characterization of residual strains in FDM process. In Residual Stress, Thermomechanics E Infrared Imaging, Hybrid Techniques and Inverse Problems; Springer: Cham, Switzerland, 2014; Volume 8, pp. $333-337$. [CrossRef]

4. Berman, B. 3-D printing: The new industrial revolution. Bus. Horizons 2012, 55, 155-162. [CrossRef]

5. Harrysson, O.L.; Cansizoglu, O.; Marcellin-Little, D.J.; Cormier, D.R.; West, H.A. Direct metal fabrication of titanium implants with tailored materials and mechanical properties using electron beam melting technology. Mater. Sci. Eng. C 2008, $28,366-373$. [CrossRef]

6. Bourell, D.L.; Leu, M.C.; Rosen, D.W. Roadmap for Additive Manufacturing Identifying the Future of Freeform Processing; The University of Texas at Austin Laboratory for Freeform Fabrication Advanced Manufacturing Center: Austin, TX, USA, 2009.

7. Mazzoli, A.; Germani, M.; Raffaeli, R. Direct fabrication through electron beam melting technology of custom cranial implants designed in a PHANToM-based haptic environment. Mater. Des. 2009, 30, 3186-3192. [CrossRef]

8. Klammert, U.; Gbureck, U.; Vorndran, E.; Rödiger, J.; Meyer-Marcotty, P.; Kübler, A.C. 3D powder printed calcium phosphate implants for reconstruction of cranial and maxillofacial defects. J. Cranio-Maxillofacial Surg. 2010, 38, 565-570. [CrossRef]

9. Melchels, F.P.; Feijen, J.; Grijpma, D.W. A review on stereolithography and its applications in biomedical engineering. Biomaterials 2010, 31, 6121-6130. [CrossRef]

10. Puri, P.M.; Khajuria, H.; Nayak, B.P.; Badiye, A. Stereolithography: Potential Applications in Forensic Science. Res. J. Eng. Sci. 2012, 1, 47-50.

11. Schrot, J.; Pietila, T.; Sahu, A. State of the art: 3D printing for creating compliant patient-specific congenital heart defect models. J. Cardiovasc. Magn. Reson. 2014, 16, W19. [CrossRef]

12. Guillotin, B.; Guillemot, F. Cell patterning technologies for organotypic tissue fabrication. Trends Biotechnol. 2011, 29, 183-190. [CrossRef]

13. Langer, R.; Vacanti, J.P. Tissue engineering. Science 1993, 260, 920-926. [CrossRef]

14. O'Brien, F.J. Biomaterials \& scaffolds for tissue engineering. Mater. Today 2011, 14, 88-95. [CrossRef]

15. Vacanti, J.P.; Morse, M.A.; Saltzman, W.M.; Domb, A.J.; Perez-Atayde, A.; Langer, R. Selective cell transplantation using bioabsorbable artificial polymers as matrices. J. Pediatr. Surg. 1988, 23, 3-9. [CrossRef]

16. Wakitani, S.; Imoto, K.; Yamamoto, T.; Saito, M.; Murata, N.; Yoneda, M. Human autologous culture expanded bone marrow mesenchymal cell transplantation for repair of cartilage defects in osteoarthritic knees. Osteoarthr. Cartil. 2002, 10, 199-206. [CrossRef] [PubMed]

17. Ikada, Y. Challenges in tissue engineering. J. R. Soc. Interface 2006, 3, 589-601. [CrossRef]

18. Anthony Atala, Wake Forest Innovations. Available online: https://www.wakeforestinnovations.com/experts/anthony-atala$\mathrm{md} /$ (accessed on 13 May 2021). 
19. Erwin, R. Facilitating 3D Organ Printing with Plant-Based BioInks, Pharma's Almanac, PAP-Q4-19-CL-018. 2019. Available online: https:/ / www.pharmasalmanac.com/articles/facilitating-3d-organ-printing-with-plant-based-bioinks (accessed on 13 May 2021).

20. Atala, A.; Bauer, S.B.; Soker, S.; Yoo, J.J.; Retik, A.B. Tissue-engineered autologous bladders for patients needing cystoplasty. Lancet 2006, 367, 1241-1246. [CrossRef]

21. Elliott, M.J.; De Coppi, P.; Speggiorin, S.; Roebuck, D.; Butler, C.R.; Samuel, E.; Crowley, C.; McLaren, C.; Fierens, A.; Vondrys, D.; et al. Stem-cell-based, tissue engineered tracheal replacement in a child: A 2-year follow-up study. Lancet 2012, 380, 994-1000. [CrossRef]

22. De Coppi, P.; Delo, D.; Farrugia, L.; Udompanyanan, K.; Yoo, J.J.; Nomi, M.; Atala, A.; Soker, S. Angiogenic Gene-Modified Muscle Cells for Enhancement of Tissue Formation. Tissue Eng. 2005, 11, 1034-1044. [CrossRef] [PubMed]

23. Dong, L.; Wang, S.-J.; Zhao, X.-R.; Zhu, Y.-F.; Yu-Fang, Z. 3D- Printed Poly(e-caprolactone) Scaffold Integrated with Cell-laden Chitosan Hydrogels for Bone Tissue Engineering. Sci. Rep. 2017, 7, 1-9. [CrossRef] [PubMed]

24. Nicodemus, G.D.; Bryant, S.J. Cell Encapsulation in Biodegradable Hydrogels for Tissue Engineering Applications. Tissue Eng. Part B Rev. 2008, 14, 149-165. [CrossRef]

25. Kantaros, A.; Karalekas, D. Fiber Bragg grating based investigation of residual strains in ABS parts fabricated by fused deposition modeling process. Mater. Des. 2013, 50, 44-50. [CrossRef]

26. Moroni, L.; de Wijn, J.; van Blitterswijk, C. 3D fiber-deposited scaffolds for tissue engineering: Influence of pores geometry and architecture on dynamic mechanical properties. Biomaterials 2006, 27, 974-985. [CrossRef] [PubMed]

27. Amirkhani, S.; Bagheri, R.; Yazdi, A.Z. Effect of pore geometry and loading direction on deformation mechanism of rapid prototyped scaffolds. Acta Mater. 2012, 60, 2778-2789. [CrossRef]

28. Leong, K.F.; Cheah, C.M.; Chua, C.K. Solid freeform fabrication of three-dimensional scaffolds for engineering replacement tissues and organs. Biomaterials 2003, 24, 2363-2378. [CrossRef]

29. Eshraghi, S.; Das, S. Mechanical and microstructural properties of polycaprolactone scaffolds with one-dimensional, twodimensional, and three-dimensional orthogonally oriented porous architectures produced by selective laser sintering. Acta Biomater. 2010, 6, 2467-2476. [CrossRef]

30. Miranda, P.; Pajares, A.; Guiberteau, F. Finite element modeling as a tool for predicting the fracture behavior of robocast scaffolds. Acta Biomater. 2008, 4, 1715-1724. [CrossRef]

31. Miranda, P.; Saiz, E.; Gryn, K.; Tomsia, A.P. Sintering and robocasting of $\beta$-tricalcium phosphate scaffolds for orthopaedic applications. Acta Biomater. 2006, 2, 457-466. [CrossRef]

32. Zhou, K.; Dong, C.; Zhang, X.; Shi, L.; Chen, Z.; Xu, Y.; Cai, H. Preparation and characterization of nanosilver-doped porous hydroxyapatite scaffolds. Ceram. Int. 2015, 41, 1671-1676. [CrossRef]

33. Rodriguez, G.; Dias, J.; D'Ávila, M.A.; Bártolo, P. Influence of Hydroxyapatite on Extruded 3D Scaffolds. Procedia Eng. 2013, 59, 263-269. [CrossRef]

34. Shuai, C.; Mao, Z.; Lu, H.; Nie, Y.; Hu, H.; Peng, S. Fabrication of porous polyvinyl alcohol scaffold for bone tissue engineering via selective laser sintering. Biofabrication 2013, 5, 015014. [CrossRef]

35. Wieding, J.; Jonitz, A.; Bader, R. The Effect of Structural Design on Mechanical Properties and Cellular Response of Additive Manufactured Titanium Scaffolds. Materials 2012, 5, 1336-1347. [CrossRef]

36. Serra, T.; Planell, J.; Navarro, M. High-resolution PLA-based composite scaffolds via 3-D printing technology. Acta Biomater. 2013, 9, 5521-5530. [CrossRef] [PubMed]

37. Cox, S.C.; Thornby, J.A.; Gibbons, G.J.; Williams, M.A.; Mallick, K.K. 3D printing of porous hydroxyapatite scaffolds intended for use in bone tissue engineering applications. Mater. Sci. Eng. C 2015, 47, 237-247. [CrossRef] [PubMed]

38. Inzana, J.A.; Olvera, D.; Fuller, S.M.; Kelly, J.P.; Graeve, O.A.; Schwarz, E.M.; Kates, S.L.; Awad, H.A. 3D printing of composite calcium phosphate and collagen scaffolds for bone regeneration. Biomaterials 2014, 35, 4026-4034. [CrossRef] [PubMed]

39. Elomaa, L.; Teixeira, S.; Hakala, R.; Korhonen, H.; Grijpma, D.W.; Seppälä, J.V. Preparation of poly( $\varepsilon$-caprolactone)-based tissue engineering scaffolds by stereolithography. Acta Biomater. 2011, 7, 3850-3856. [CrossRef] [PubMed]

40. Gauvin, R.; Chen, Y.-C.; Lee, J.W.; Soman, P.; Zorlutuna, P.; Nichol, J.W.; Bae, H.; Chen, S.; Khademhosseini, A. Microfabrication of complex porous tissue engineering scaffolds using 3D projection stereolithography. Biomaterials 2012, 33, 3824-3834. [CrossRef] [PubMed]

41. Lowther, M.; Louth, S.; Davey, A.; Hussain, A.; Ginestra, P.; Carter, L.; Eisenstein, N.; Grover, L.; Cox, S. Clinical, industrial, and research perspectives on powder bed fusion additively manufactured metal implants. Addit. Manuf. 2019, 28, 565-584. [CrossRef]

42. Zein, I.; Hutmacher, D.W.; Tan, K.C.; Teoh, S.H. Fused deposition modeling of novel scaffold architectures for tissue engineering applications. Biomaterials 2002, 23, 1169-1185. [CrossRef]

43. Ozbolat, I.T.; Hospodiuk, M. Current advances and future perspectives in extrusion-based bioprinting. Biomaterials 2016, 76, 321-343. [CrossRef]

44. Li, X.; Liu, B.; Pei, B.; Chen, J.; Zhou, D.; Peng, J.; Zhang, X.; Jia, W.; Xu, T. Inkjet Bioprinting of Biomaterials. Chem. Rev. 2020, 120, 10793-10833. [CrossRef]

45. Ng, W.L.; Lee, J.M.; Yeong, W.Y.; Naing, M.W. Microvalve-based bioprinting_Process, bio-inks and applications. Biomater. Sci. 2017, 5, 632-647. [CrossRef] 
46. Ng, W.L.; Lee, J.M.; Zhou, M.; Chen, Y.-W.; Lee, K.-X.A.; Yeong, W.Y.; Shen, Y.-F. Vat polymerization-based bioprinting-process, materials, applications and regulatory challenges. Biofabrication 2019, 12, 022001. [CrossRef] [PubMed]

47. Zhuang, P.; Ng, W.L.; An, J.; Chua, C.K.; Tan, L.P. Layer-by-layer ultraviolet assisted extrusion-based (UAE) bioprinting of hydrogel constructs with high aspect ratio for soft tissue engineering applications. PLoS ONE 2019, 14, e0216776. [CrossRef] [PubMed]

48. Li, Q.; Lei, X.; Wang, X.; Cai, Z.; Lyu, P.; Zhang, G. Hydroxyapatite/Collagen Three-Dimensional Printed Scaffolds and Their Osteogenic Effects on Human Bone Marrow-Derived Mesenchymal Stem Cells. Tissue Eng. Part A 2019, 25, 1261-1271. [CrossRef] [PubMed]

49. Cheah, C.; Chua, C.; Leong, K.F.; Chua, S.W. Development of a Tissue Engineering Scaffold Structure Library for Rapid Prototyping. Part 1: Investigation and Classification. Int. J. Adv. Manuf. Technol. 2003, 21, 291-301. [CrossRef]

50. Wettergreen, M.; Bucklen, B.; Starly, B.; Yuksel, E.; Sun, W.; Liebschner, M. Creation of a unit block library of architectures for use in assembled scaffold engineering. Comput. Des. 2005, 37, 1141-1149. [CrossRef]

51. Hutmacher, D.W. Scaffolds in tissue engineering bone and cartilage. Biomaterials 2000, 21, 2529-2543. [CrossRef]

52. Brown, B.N.; Valentin, J.E.; Stewart-Akers, A.M.; McCabe, G.P.; Badylak, S.F. Macrophage phenotype and remodeling outcomes in response to biologic scaffolds with and without a cellular component. Biomaterials 2009, 30, 1482-1491. [CrossRef]

53. Yannas, I.V.; Lee, E.; Orgill, D.P.; Skrabut, E.M.; Murphy, G.F. Synthesis and characterization of a model extracellular matrix that induces partial regeneration of adult mammalian skin. Proc. Natl. Acad. Sci. USA 1989, 86, 933-937. [CrossRef]

54. Murphy, C.M.; O’Brien, F.J. Understanding the effect of mean pore size on cell activity in collagen-glycosaminoglycan scaffolds. Cell Adhes. Migr. 2010, 4, 377-381. [CrossRef]

55. Martin, Y.; Vermette, P. Bioreactors for tissue mass culture: Design, characterization, and recent advances. Biomaterials 2005, 26, 7481-7503. [CrossRef]

56. Raimondi, M.T.; Moretti, M.; Cioffi, M.; Giordano, C.; Boschetti, F.; Laganà, K.; Pietrabissa, R. The effect of hydrodynamic shear on 3D engineered chondrocyte systems subject to direct perfusion. Biorheology 2006, 43, 215-222. [PubMed]

57. Boschetti, F.; Raimondi, M.T.; Migliavacca, F.; Dubini, G. Prediction of the micro-fluid dynamic environment imposed to three-dimensional engineered cell systems in bioreactors. J. Biomech. 2006, 39, 418-425. [CrossRef] [PubMed]

58. Naing, M.; Chua, C.; Leong, K.F.; Wang, Y. Fabrication of customised scaffolds using computer-aided design and rapid prototyping techniques. Rapid Prototyp. J. 2005, 11, 249-259. [CrossRef]

59. Wubneh, A.; Tsekoura, E.K.; Ayranci, C.; Uludağ, H. Current state of fabrication technologies and materials for bone tissue engineering. Acta Biomater. 2018, 80, 1-30. [CrossRef]

60. Barba, A.; Maazouz, Y.; Diez-Escudero, A.; Rappe, K.; Espanol, M.; Montufar, E.B.; Öhman-Mägi, C.; Persson, C.; Fontecha, P.; Manzanares, M.-C.; et al. Osteogenesis by foamed and 3D-printed nanostructured calcium phosphate scaffolds: Effect of pore architecture. Acta Biomater. 2018, 79, 135-147. [CrossRef] [PubMed]

61. Kantaros, A.; Chatzidai, N.; Karalekas, D. 3D printing-assisted design of scaffold structures. Int. J. Adv. Manuf. Technol. 2016, 82, 559-571. [CrossRef]

62. Habib, F.N.; Iovenitti, P.; Masood, S.H.; Nikzad, M. Fabrication of polymeric lattice structures for optimum energy absorption using Multi Jet Fusion technology. Mater. Des. 2018, 155, 86-98. [CrossRef]

63. Hollister, S.J. Scaffold Design and Manufacturing: From Concept to Clinic. Adv. Mater. 2009, 21, 3330-3342. [CrossRef]

64. Krishna, L.; Kamal, M.; Venkatesh, S. Design and manufacturing of a scaffold for biomedical applications using additive manufacturing. Indian J. Sci. Res. 2017, 15, 1-6.

65. Ning, L.; Chen, X. A brief review of extrusion-based tissue scaffold bio-printing. Biotechnol. J. 2017, 8. [CrossRef]

66. Nurulhuda, N. Fabrication PEGDA/ANFs Biomaterial as 3D Tissue Engineering Scaffold by DLP 3D Printing Tecshnology. Int. J. Eng. Adv. Technol. 2019, 8, 751-758. [CrossRef]

67. Taylor, S.L.; Ibeh, A.J.; Jakus, A.E.; Shah, R.N.; Dunand, D.C. NiTi-Nb micro-trusses fabricated via extrusion-based 3D-printing of powders and transient-liquid-phase sintering. Acta Biomater. 2018, 76, 359-370. [CrossRef] [PubMed]

68. Yang, Y.; Chu, L.; Yang, S.; Zhang, H.; Qin, L.; Guillaume, O.; Eglin, D.; Richards, R.G.; Tang, T. Dual-functional 3D-printed composite scaffold for inhibiting bacterial infection and promoting bone regeneration in infected bone defect models. Acta Biomater. 2018, 79, 265-275. [CrossRef] [PubMed]

69. Hu, Y.; Wang, J.; Li, X.; Hu, X.; Zhou, W.; Dong, X.; Wang, C.; Yang, Z.; Binks, B.P. Facile preparation of bioactive nanoparticle/poly ( $\varepsilon$-caprolactone) hierarchical porous scaffolds via $3 \mathrm{D}$ printing of high internal phase Pickering emulsions. $J$. Colloid Interface Sci. 2019, 545, 104-115. [CrossRef] [PubMed]

70. Alison, L.; Menasce, S.; Bouville, F.; Tervoort, E.; Mattich, I.; Ofner, A.; Studart, A.R. 3D printing of sacrificial templates into hierarchical porous materials. Sci. Rep. 2019, 9, 1-9. [CrossRef]

71. Minas, C.; Carnelli, D.; Tervoort, E.; Studart, A.R. 3D Printing of Emulsions and Foams into Hierarchical Porous Ceramics. Adv. Mater. 2016, 28, 9993-9999. [CrossRef]

72. Lefevere, J.; Protasova, L.; Mullens, S.; Meynen, V. 3D-printing of hierarchical porous ZSM-5: The importance of the binder system. Mater. Des. 2017, 134, 331-341. [CrossRef]

73. Ng, W.L.; Goh, M.H.; Yeong, W.Y.; Naing, M.W. Applying macromolecular crowding to 3D bioprinting: Fabrication of 3D hierarchical porous collagen-based hydrogel constructs. Biomater. Sci. 2018, 6, 562-574. [CrossRef] 
74. Chen, Y.W.; Shen, Y.F.; Ho, C.C.; Yu, J.; Wu, Y.H.A.; Wang, K.; Shih, C.T.; Shie, M.Y. Osteogenic and angiogenic potentials of the cell-laden hydrogel/mussel-inspired calcium silicate complex hierarchical porous scaffold fabricated by 3D bioprinting. Mater. Sci. Eng. C 2018, 91, 679-687. [CrossRef]

75. Kovalcik, A.; Sangroniz, L.; Kalina, M.; Skopalova, K.; Humpolíček, P.; Omastova, M.; Mundigler, N.; Müller, A.J. Properties of scaffolds prepared by fused deposition modeling of poly(hydroxyalkanoates). Int. J. Biol. Macromol. 2020, 161, 364-376. [CrossRef]

76. Odde, D.J.; Renn, M.J. Laser-guided direct writing of living cells. Biotechnol. Bioeng. 2000, 67, 312-318. [CrossRef]

77. Pardo, L.; Wilson, J.W.C.; Boland, T. Characterization of Patterned Self-Assembled Monolayers and Protein Arrays Generated by the Ink-Jet Method. Langmuir 2003, 19, 1462-1466. [CrossRef] 